\title{
Ocorrência de cupins (Insecta, Isoptera) como pragas de mandioca em Bujaru, Pará
}

\author{
Adelmar Gomes Bandeira (")
}

\section{Resumo}

Com o objetivo de constatar estragos em mandioca, suspeitas de serem causados por cupins, numa área do Município de Bujaru, foram arrancadas e analisadas aproximadamente 200 plantas de diferentes cultivares de mandioca em 6 roçados. Foram escolhidas as plantas que apresentavam algum sintoma de doença. Foram também plantadas 1.025 estacas de mais de $10 \mathrm{cul}$ tivares e observadas por 10 meses, na área de ocorrência de cupins em mandiocais. Constatou-se que Heterotermes tenuis e Coptotermes testaceus são pragas naquela área e que Syntermes dirus e Nasutitermes cor. niger são suspeitos de também contribuir com uma pro. porção menor de estragos. Constatou-se a ocorrência de cupins em mandioca também em outros municípios do Pará, mas sempre em menor escala.

\section{INTRODUÇÃo}

Mandioca (Manihot esculenta) é a principal cultura de subsistência da Amazônia Brasileira. Seu uso na região é três vezes maiơr que o do trigo, batata, arroz e soja reunidos (Albuquerque \& Cardoso, 1979). Ela é utilizada como alimento tanto humano como de animais domésticos. Entre as várias formas como a mandioca é geralmente utilizada, a farinha tem sido o principal produto. Além da utilidade cơmo alimento, atualmente tem-se dado ênfase à produção de álcool combustivel, como substituto do petróleo, a partir da fermentação da mandioca (Dantas, 1979). Com o crescimento da população brasileira e mais especificamente da Amazônia, a demanda de alimentos e combustíveis nesta região certamente aumentará e, como conseqüência, há a necessidade de melhor aproveitamento do potencial agrícola da terra. A mandioca, que é uma cultura de ciclo relativamente curto e perfeitamente adaptada aos solos e clima locais, certamente será cultivada em maior escala para atender a essa crescente demanda. Pesquisas sobre melhora- mento e produção, incluindo-se a proteção contra eventuais pragas, deverão acompanhar o processo evolutivo do cultivo da mandioca.

Na Amazônia, a saúva (Atta sp.) foi considerada por Albuquerque (1970) a mais impo:tante praga de implicações econômicas. O cupim, muito embora tenha sido atribuído como praga em vários países (Bellotti \& Schoonhoven, 1978), até o momento parece ainda não ter sido registrado como praga de mandioca na Amazônia Brasileira. Em 1978, tomou-se conhecimento de ataques por cupins em alguns roçados do município de Bujaru, despertandose a atenção para tal fato. Desde então, iniciaram-se algumas observações sobre o assunto. cujos resultados são apresentados neste trabalho.

\section{MATERIAIS E MÉTODOS}

As observações foram feitas em 6 roçados no município de Bujaru. Aproximadamente 200 plantas apresentando amarelidão, folhas murchas, ou plantas tombadas foram arrancadas para exames. As raízes tuberosas e o caule foram triturados em pequenos pedaços para verificar-se a presença de cupins e outros insetos.

Em 12 de junho de 1979, foram plantadas 1.025 estacas de maniva das cultivares "Amazonas", "CM-341", "Encarnadinha", "Engana Ladrão", "Jaraqui", "Mameluca Branca", “Maranhense", "Niplê", "Rainha do Sol" e "Riqueza". Estas cultivares foram adquiridas do CPATU/EMBRAPA, Belém. Mais 7 cultivares adquiridas dos próprios roçados com problemas de pragas também foram plantadas, algumas das quais podendo ser das mesmas do CPATU. Foram feitas 4 limpezas, a primeira 2 meses após o plantio, feita de enxada; as subseqüentes foram feitas com terçado. No déci-

(") - INPA - Museu Paraense Emílio Goeldi. Belém. 
mo mês, a mandioca foi arrancada para observação. (Mandioca na Amazônia é comumente colhida em torno de um ano até ano e meio de idade) .

Durante o período deste experimento, vários outros roçados foram visitados, em diferentes iocalidades do Estado do Pará e foram feitas observações, buscando constatar a presença da praga.

Os insetos coletados no decorrer deste trabalho encontram-se depositados na coleção entomológica do Museu Paraense Emílio Goeldi, Belém.

\section{RESUlTADOS E DISCUSSÕES}

As espécies de cupins Heterotermes tenuis e Coptotermes testaceus foram encontradas com relativa freqüência em mandiocais no município de Bujaru. As duas espécies apresentaram ocorrência muito variada: Num roçado, uma era mais freqüente, podendo o inverso ocorrer no próximo roçado. $\mathrm{Na}$ área experimental, por exemplo, $H$. tenuis ocorreu 4 vezes mais que $C$. testaceus.

Observando-se plantas em vários estágios de ataque por cupins, pareceu mais ou menos evidente que os Isoptera penetram pelas raizes tuberosas. Isso porque nas plantas recentemente infestadas, os insetos não foram encontrados em outras partes. Os cupins podem penetrar nas raízes sãs, perfurando-as por um? lado. Após infestadas, as raízes podem começar a apodrecer e ficar muito umedecidas, dando lugar ao aparecimento de outros insetos, principalmente formas larvais de Coleoptera e Diptera. Se o apodrecimento atingir um estágio muito avançado, os cupins se transferem para outras raízes ou se direcionam para o caule, através da medula. Todas as cultivares de mandioca sofreram estragos, porém não se sabe se há preferência por alguma em particular, pois os dados são insuficientes para se tirar qualquer conclusão. As plantas com aparência de doentes nem sempre continham cupins. Ao contrário, outras aparentemente sãs, às vezes, estavam com as raízes quase totalmente estragadas.

De uma pequena amostragem de outros insetos encontrados em raízes podres, asso- ciados com cupins, encontraram-se os seguintes: Coleoptera - larvas de Anobiidae, Carabidae, Curculionidae, Elateridae, Tenebrionidae e adultos de Nitidulidae (?); Diptera - larvas de Otitidae, Scirridae e Stratiomyidae (gên. Pachygaster e outros (?)). Estes grupos talvez não sejam realmente pragas, pois parece que se aproveitam apenas de raízes já estragadas para delas se alimentarem (alguns talvez sejam predadores). Os cupins parecem ser as verdadeiras pragas, ou pelo menos as mais expressivas, nessa área.

Heterotermes e Coptotermes são comumente encontrados em madeira morta em decomposição (Bandeira, 1979). Por este motivo, as espécies de Coptotermes têm-se beneficiado do transporte de madeiras pelo homem para se distribuirem praticamente por todas as regiōes zoogeográficas do planeta, causando sérios problemas (Harris, 1971; Emerson, 1955; Araujo, 1977). Harris cita a ocorrência de vá. rias espécies de Coptotermes no Brasil, muitas delas consideradas pragas de madeira e inclusive de árvores vivas de seringueira (Hevea sp.). Duas espécies (C. voeltzkowi e $C$. paradoxus) são citadas como pragas de mandioca em Madagascar (Bellotti \& Schoonhoven, 1978)

Das 1.025 estacas de maniva plantadas para observações, somente $528(51.5 \%)$ sobreviveram, nos três primeiros meses. Não se sabe ao certo o que aconteceu com as demais, porém acredita-se que, em grande parte, não tenham realmente nascido, sendo a causa discutível. Essas 528 plantas foram zeladas e no décimo mês mais 34 haviam sido extintas, algumas delas tendo sido observadas com cupins, após o terceiro mês. As 494 plantas restantes foram arrancadas e examinadas no décimo mês: $12(2,5 \%)$ dessas continham $H$. tenuis nas raizes e/ou no caule; $3(<1 \%)$ continham C. testaceus e outras $34(6,9 \%)$ apresentavam danos, pelo menos em algumas raízes, e, às vezes, no caule também, semelhantes aos causados por cupins, mas esses não foram encontrados. As plantas que morreram e as que sofreram estragos, atribuídos principalmente a cupins, totalizaram $83(15,7 \%)$, das 528 sobreviventes até o terceiro mês. A percentagem de perdas logicamente deveria ainda aumentar. pois os cupins devem transferir-se de uma à medida que a cultura se tornasse mais velha, 
planta estragada a outra, sã, para garantir suaa sobrevivência. Isso foi evidenciado, quando observadas culturas em roçados com mais de um ano, onde os estragos podiam alcançar níveis superiores aos da área experimental.

Saúva, considerada a principal praga de mandioca no Estuário Amazônico (Albuquerque, 1970), praticamente não apresentou estragos, pois alguns ninhos que existiam nos arredores da área experimental foram controlados desde o início com formicida.

Foram encontrados cupins em mandioca também em outras localidades do Estado do Pará, mas sempre em escala bem menor, ge. ralmente sem implicação econômica. $H$. tenuis foi encontrado no Município de Benevides; $C$. testaceus, em Castanhal e Ruptitermes sp., em Bragança.

Estas duas espécies de cupins $-H$. tenuis e C. testaceus - são muito comuns, possivelmente em toda a Amazônia. São espécies encontradas principalmente na floresta densa, de terra firme, mas são também comuns em ambientes modificados pelo homem, tais como pastagens e roçados, desde que o ambiente de origem tenha sido floresta do tipo citado e que haja madeira em decomposição, pois estas duas espécies têm papel importante na reciclagem da matéria orgânica vegetal. A razăo por que esses cupins tiveram mais preferência por mandioca em Bujaru do que nas outras localidades que se tem notícia é assunto a ser esclarecido. Sabe-se, porém, que as condições edáficas têm influência sobre a aparição de certas pragas, principalmente quando a cultura não chega a desenvoiver-se bem (Albuquerque. 1969)

A porosidade dos solos da Amazônia é mantida principalmente pelas raízes e pequenos animais a elas associados (Schubart, 1977: Bandeira, 1979a). A prática agrícola de aração dos solos seria, portanto, prejudicial nesse aspecto. Teoricamente poderia ter efeitos na redução das populações dos "cupins da madeira úmida", em cujo grupo estão incluídos os cupins pragas aqui citados. Por outro lado, se os Isoptera conseguissem sobreviver, os danos poderiam eventualmente ser grandes, pois a fonte de alimentos seria constituída quase que exclusivamente da própria mandioca. Seria in. teressante, todavia, mais pesquisa sobre este assunto, em que seriam estudadas culturas de mandioca em solos arados e não arados para comparação. Paralelamente seria importante procurar-se obter clones resistentes a pragas.

\section{AGRADECIMENTOS}

Ao Milton de Albuquerque (CPATU / EMBRAPA), pelo fornecimento de manivas para plantio e por críticas ao manuscrito; a W. L. Overal, I. S. Gorayeb e Paulo T. R. Nascimento (Museu Emilio Goeidi), pela identificação dos coleópteros e dípteros e sugestões durante a pesquisa; a Mário Dantas (CPATU/EMBRA. PA), pela leitura e críticas ao manuscrito; ao Ramiro Bittencourt Neto (Museu Emílio Goeldi), pela ajuda nos trabalhos de campo.

\section{SUMMARY}

In order to verify suspected damage to cassava (Manihot esculenta) by termites in fields in the municipality of Bujaru, Pará State, Brazil, about 200 apparently diseased plants of different cultivares were uprooted and inspected. Several of these plants contained termites in the tuber or stem, 1,025 cuttings, representing more than 10 cultivares, were planted in a field where termites had been found and were harvested after 10 months. Heterotermes tenuis and Coptotermes testaceus were found to be pests, and Syntermes dirus and Nasutitermes corniger were also suspected of contributing to the observed crop damage. Termites were found in cassava in other areas of Pará State, but álways on a smaller scale.

\section{REFERÊNCIAS BIBLIOGRÁFICAS}

AlbuQuerque, M.

1969 - A mandioca na Amazônia. I - Noçōes gerais sobre a cultura. II - A cultura na Amazônia. Belém, SUDAM. 227 p.

1970 - Mandioca. IPEAN, Série: Fitotecnia, Belém, 1(2) : 1-65.

Albuquerque, M. \& Cardoso, E.N.R.

1979 - A mandioca no Trópico Úmido. Belém, CPATU/EMBRAPA, 300 p. (Datilografado).

Araujo, R.L.

1977 - Catálogo dos Isoptera do Novo Mundo. Rio de Janeiro, Academia Brasileira de Ciências. $92 \mathrm{p}$.

BANDEtra, A.G.

1979 - Notas sobre a fauna de cupins (Insecta Isoptera) do Parque Nacional da Amazônia (Tapajós), Brasil. Bol. Mus. Paraense Emilio Goeldi, Nova Série: Zoologia, (96) : 1-12. 
1979a - Ecologia de cupins (Insecta, Isoptera) da Amazônia Central: efeitos do desmatamento sobre as populações. Acta Amazonica, $9(3): 481-499$.

Bellotti, A.B. \& Schoonhoven, A.

1978 - Mite and insect pests of cassava. Ann. Rev. Entomol., $23: 39-67$.

DANTAS, R.B.

1979 - Alcool e outras fontes alternativas de energia como substitutivas de petróleo $\left(2 .^{a}\right.$ parte). Brasil Açucareiro, 94(5) : 26-42.
EMERSON, A.E.

1955 - Geographical origins and distributions of termite genera. Fieldiana: Zoology, 37: 465-521.

HARRIS, W.V.

1971 - Termites: their recognition and control, 2 ed. London, Longman Group Ltd. :96 p.

SCHUBART, H.O.R.

1977 - Critérios ecológicos para o desenvolvimento agrícola das terras-firmes da Ainazônia. Acta Amazonica, 7(4): 559-567.

(Aceito para publicação em 4/06/80) 